\title{
SOME THOUGHTS ON INFLUENCE OF PRESSURE AND THERMAL HISTORY ASSUMPTIONS ON PETROLEUM SYSTEM MODELLING
}

\author{
A. D. Carr $^{* 1,2}$ C. N. Uguna ${ }^{3,4}$ \\ 1 Advanced Geochemical Systems Ltd., 1 Towles Fields, Burton on the Wolds, \\ Loughborough, Leics. LE12 5TD. UK. \\ 2 Global Exploration Services Ltd., Little Lower Ease, Cuckfield Road, Ansty, \\ Haywards Heath, West Sussex. RH17 5AL. UK. \\ 3 Faculty of Engineering, University of Nottingham, Energy Technologies \\ Building, Innovation Park, Jubilee Campus, Triumph Road, Nottingham, NG7 2TU, \\ UK. \\ 4 Centre for Environmental Geochemistry, British Geological Survey, \\ Keyworth, Nottingham, NG12 5GG, UK. \\ *:ac.ags@btconnect.com, andy@globalexplor.com
}

\begin{abstract}
The use of petroleum system modelling (PSM) requires the integration of the geological sciences with petroleum engineering, physics and chemistry. In a recent study, Mahanfane et al. (2014) applied 1-D PSM to the study of maturation and petroleum generation in northern Mozambique. However, PSM cannot divorce itself from the fundamental laws of mechanics and thermodynamics when attempting to derive a thermal history to be used for the modelling of maturation and petroleum generation. As will be shown in this paper, the application of mechanics and thermodynamics to the derivation of the thermal history will require some radical changes to the methods used in PSM.

Mechanics and thermodynamics require a reducing heat flow during subsidence, but require an increased heat flow during inversion. The reason for the failure to apply mechanics and thermodynamics during thermal history derivation in PSM arises from the failure to incorporate the effects of pressure into the kinetic models used for predicting maturation and petroleum generation. Pressure increases the activation energy of endothermic reactions, e.g., maturation and petroleum generation, in the kinetic model used to predict the reaction rate, and results in higher temperatures being required to produce the same transformation ratio as would be required for the current temperature-time kinetic models. Incorporating pressure should enable the same thermal history obtained from tectonic history-mechanicthermodynamic models to be used as those used to calibrate the thermal history using maturity parameters, e.g., vitrinite reflectance.
\end{abstract}




\section{KEYWORDS}

Petroleum system modelling (PSM), kinetics, thermal history derivation, mechanics, thermodynamics.

\section{INTRODUCTION}

This paper arises from some thoughts derived from physics and chemistry regarding the thermal history assumptions undertaken during petroleum system modelling (PSM). This paper outlines some of the physical principles that need to be followed before the thermal history model can be derived for use in PSM. It is not the intention of this model to discuss the relative merits of the numerous kinetic models developed using pyrolysis of kerogens and source rocks over the years, nor the problems associated with the different pyrolysis methods, e.g. sample type and size, heating rate, temperature measurement, etc., which have been already been widely discussed (e.g., e.g. Snowdon, 1979; Burnham et al., 1987; Jarvie, 1991; Stainforth, 2009). The maturity and petroleum systems modelling study in the offshore Zambezi Delta and Angoche Basin, northern Mozambique (Mahanjane et al., 2014), was used as the basis for the comments regarding the necessity to derive the thermal history from the tectonic and burial histories, in combination with temperature and maturity data. Mahanjane et al. (2014) derived the thermal history using measured vitrinite reflectance values from four wells, calibrated with values predicted by kinetic model. The modelling indicates that while deeply-buried Jurassic and Lower Cretaceous source rocks were overmature for both oil and gas generation, these source rocks in the remaining parts of the study area are mature for petroleum generation. The aim of this paper is to illustrate some of the flaws that are present in PSM, as regards the failure to use mechanical and thermodynamic laws when deriving the thermal history that is used to predict timing, volume and phase of petroleum generated.

\section{COMENTS}

1. The paper by Mahanjane et al. (2014) is clear and well presented, and represents a typical approach to petroleum systems modelling as currently used in basin evaluation before and during petroleum exploration. Having identified the source rock(s) present, the modeller is required to produce a thermal history model so that both petroleum generation and maturation in the modelled well/section/basin can be derived. The thermal history is derived from the burial history combined with vitrinite reflectance (Vr) data measured from wells. The purpose of this calibration is to ensure that the thermal history model is able correctly to predict the measured Vr data. Mahanjane et al. (2014) modelled four wells (Nemo-1, Sofala- 
1X, Mambone-1 and Divinhe-1) and obtained good calibrations between the predicted and measured Vr values in each of the wells. The present-day heat flows presumably adequately predict the well temperatures, although this temperature-depth calibration was not shown for any of the wells. Taking the Mambone- 1 and Divhine- 1 wells as examples, the burial histories (Figs. 8a and b in Mahanjane et al. respectively) show that the basement (i.e., the basal layer) has subsided to present day depths of 3.8 and $4.2 \mathrm{~km}$, respectively. The thermal history, however, shows that this subsidence has occurred under a constant heat flow history.

2. A basin subsides when the downward force provided by the sediment (and water) load exceeds the upward force provided by the basement and mantle beneath the subsiding basin. As the upward force changes, so the mechanical energy (work) associated with this upward force also changes, where energy is the capacity to do work, i.e., energy = work. It is impossible to generate mechanical energy without also generating heat. As a basin subsides so the heat flow supplied from the basement and deeper parts of the earth must also decrease, since the thermal energy supplied to the basin is derived from thermal energy contained in the mass beneath the basin, which consists of thermal energy derived from earth's formation processes (primordial heat), and radiogenic energy mainly generated within the basement and mantle. As this sub-basin mass is reduced, so the original mass is replaced by cooler mass that moves downwards, and this combined with the reduced radiogenic thermal energy reduces the heat flow into the basin. The rate of heat flow decrease is proportional to the rate of subsidence (Fig. 1a).

3. The relationship between subsidence and reducing heat flows is consistent with the subsidence and associated heat flow curves shown in the McKenzie (1978) tectonic model. In the post-rift stage of this model, subsidence occurs through volume contraction as the basin and crust cool. A petroleum systems model must therefore not only account for the physical characteristics of the model, i.e., compaction to predict the thickness of the various layers, well temperatures and maturity, but must also be consistent with the mechanics; thus, PSM must obey the physical laws related to movement and thermal energy. By using constant history thermal models that ignore mechanics and thermodynamics, then the conclusion must be that each cubic metre of rock can be at two different temperatures at the same movement in time, since the thermal history derived from a tectonic-mechanicalthermodynamics model is different from that predicted by the kinetic calibration methods, which is the method used by Mahanjane et al (2014) to derive the thermal history. 
4. During basin inversion, the upward force increases and this is associated with a rise in heat flow, again due to the impossibility of generating the mechanical work required to uplift the basin without generating additional amounts of heat (Fig. 1b). Uplift caused by compression in the crust generates friction, thereby increasing the heat flow. The increase in heat flow during inversion is also consistent with thermodynamics, since without increasing heat flow, the uplifted rocks gain low-entropy potential energy at the expense of higherentropy thermal energy. Without the increase in heat flow, the rock section being uplifted would show a negative entropy change, which violates the second law of thermodynamics. Although the uplifted rocks still lose thermal energy by cooling, the amount of cooling is less than if the process occurred with a constant heat flow. The increased heat flow required during uplift decreases as the upward movement ceases, falling to the value controlled by the amount of mass beneath the basin, but without the heat generated by the friction (work) required to produce the inversion.

5. For the Mambone-1 and Divhine-1 wells in the Mahanjane et al. (2014) paper, there appear to have been uplift and erosional events during the Cretaceous, Paleocene and Oligocene in both wells. The stratigraphic chart (Fig. 4, Mahanjane et al., 2014) indicates that tectonic uplift occurred during the Cretaceous, between 118 and 100 Ma. The basePaleocene unconformity ( 66 Ma) occurs as a result of erosion associated with major, late highstand regression, while the base-Oligocene unconformity was produced by uplift and doming, which preceded Miocene rifting of the East Africa Rift System. Thus the thermal models used to predict source rock maturation in both wells do not appear to be consistent with mechanical principles, and they appear to be incorrect simulations of the thermal histories at these locations.

6. The reason for the failure by petroleum systems modellers to use mechanical principles when deriving the thermal history appears to be due to the use of the EASY\%Ro kinetic model (Sweeney and Burnham, 1990) to calibrate the predicted and measured vitrinite reflectance (Vr) data. The use of a maturity parameter, e.g., Vr, together with well temperature data to calibrate the thermal history follows the methodology used to predict the temperature history (Welte et al., 1997; Waples, 1998; Harris and Peters, 2012). Apart from EASY\%Ro, there are other kinetic models available for Vr modelling, e.g., Middleton (1982), Ritter (1984), Anita (1986), Wood (1988) and Larter (1988), although all of these 
models are temperature-time (T-t) dependent. In addition, other maturity parameters, such as apatite fission track data and molecular biomarkers, can be used in place of, or together with Vr. Again, these parameters are predicted using kinetic models (see Harris and Peters, 2012). The use of multiple indicators to derive the thermal history is recommended, because each provides a different perspective on the thermal history (Waples et al., 1992).

7. Physical chemistry, however, indicates that endothermic reactions (including source rock maturation) are controlled not only by temperature and time but also by the pressure of the system. The kinetic models contain a measure of the thermal barrier (referred to as the activation energy, $E_{a}$ ) which must be overcame by increasing the temperature for the reaction to occur. High pressures should retard endothermic reactions according to le Chatelier's principle. However most of the early experimental investigations into the effect of pressure on source rock maturation as reviewed by Uguna et al. (2012) showed that it had little or only a minor effect on the reaction rate. This difference between the thermodynamically predicted and observed experimental results arises due to problems with the experimental design (Carr et al., 2009; Uguna et al., 2012).

8. The most commonly used experimental investigations into the effects of pressure have used gold bags, and this method has also been used to derive petroleum generation kinetics. In this method, the sample to be pyrolysed is sealed inside a gold-bag by welding the ends of the bag together, having removed all the vapour from inside the bag before sealing. The bag is then placed into a sealed vessel in which water surrounding the gold-bag is raised to the temperature and pressure of the experiment. At the end of the experiment after the experimental vessel has been allowed to cool, the petroleum products generated inside the gold-bag are released by puncturing the bag in a vacuum line, and the products analysed to determine composition and amount. When the effect of pressure on petroleum generation and maturation was considered, it was concluded that pressure either had no or minimal effect (e.g., Monthioux et al., 1986; Michels et al., 1994; Knauss et al., 1997). However the results obtained by this method have the same intrinsic flaw as those for most laboratory generated kinetics, which are then used to predict petroleum generation in basins (e.g., Mahanjane et al., 2014). The intrinsic flaw is the compensation between the experimentallymathematically derived values for the activation energy $\left(E_{a}\right)$ and the pre-exponential factor (A) in the Arrhenius equation (Stainforth, 2009). The results from such a set of gold-bag experiments are shown in Fig. 2. 
9. In experiments undertaken at $380{ }^{\circ} \mathrm{C}$ for $24 \mathrm{hr}$ on two Chinese coals (Tao et al., 2010), the methane and total gas yields increase with increasing pressure, trends that are not consistent with Le Chatelier's principle. Thus, changing $(\mathrm{P}, \mathrm{T})$ conditions inside the gold-bags results in an apparently incorrect thermodynamic trend, since the gas yields would be expected to have been reduced with increasing pressure. Therefore in addition to the problem of compensation effect present on $E_{a}$ and A values, the gold-bag method also appears to be influenced by a thermodynamic problem. More importantly, if the thermodynamics are a problem, then the kinetics must also be a problem, since the $\mathrm{E}_{\mathrm{a}}$ is controlled by the enthalpy and $\mathrm{A}$ by the entropy (Carr et al., 2009).

10. Experimental work using only a source rock sample and water under high pressure (as in a sedimentary basin) shows that high water pressures retard petroleum generation and maturation (Fig. 3) (Uguna et al., 2012, 2015). The main effect of pressure is to increase the activation energy $\left(E_{a}\right)$ as the pore pressure increases, due to the effect that pressure has on the $\mathrm{pV}$ component (part of the enthalpy) within $\mathrm{E}_{\mathrm{a}}$. A comparison between a kinetic model that includes the pressure effect (i.e., a T-P-t model) and one that does not (i.e., current T-t models), and with both using the same thermal history, would show that the T-P-t kinetic model predicts lower values for $\mathrm{Vr}$ and volume of petroleum generated at a given time. The effect of using the pressure controlled kinetics therefore would be to increase the amount of thermal energy required for a given amount of a reaction to occur, i.e., the transformation ratio in the case of petroleum generation, or Vr in the case of maturation. This additional thermal energy should enable the heat flow history devised using the tectonic-mechanicthermodynamic model which would involve using elevated heat flows during the Jurassic extension (ignored in the Mahanjane et al. (2014) study of the Mambone-1 and Divhine-1 wells) to be incorporated into the thermal model.

11. Carr and Petersen (2004) used the PresRo ${ }^{\circledR}$ model for a case study in the Danish Central Graben which underwent extension during the Middle Jurassic, uplift during the Early Cretaceous, and subsequent continuous subsidence to present day. The PresRo ${ }^{\circledR}$ model (Carr, 1999, 2000) reduced the pre-exponential (A) factor with increasing overpressure, but did not modify the $\mathrm{E}_{\mathrm{a}}$ term. 
12. Zou and Peng (2000), in contrast, devised a model for pressure retardation of Vr (T-PRo) in which $E_{a}$ is increased by the overpressure. T-P-Ro was used to model the LD3011 well in the Yinggehai Basin (offshore eastern China), although two different constant geothermal gradients were used to account for the period up to the Pliocene (5.2 Ma), followed by a higher gradient to reflect renewed rifting during the Pliocene.

13. Both the PresRo ${ }^{\circledR}$ and T-P-Ro models are flawed because they only use overpressure. However, as pore pressure is a force/area measurement, the effect of $100 \mathrm{MPa}$ of pore pressure on kerogen is the same, regardless of whether it is a combination of hydrostatic and overpressure or just hydrostatic pressure. Therefore, any kinetic model that incorporates pressure into its parameters must use pore pressure and not overpressure. Currently no kinetic models for predicting either petroleum generation or maturation that incorporate pressure have been developed, and these are topics requiring further research.

14. In contrast, the 1-D models for both the Nemo-1X and Sofala-1X wells (Figs. 7a and b respectively in Mahanjane et al., 2014) used a McKenzie-type (1978) decaying heat flow history after the peak heat flow at $166 \mathrm{Ma}$. A constant heat flow was used in the onshore Mambone- 1 and Divhine- 1 wells which have present-day heat flows of 60 and $70 \mathrm{~mW} / \mathrm{m}^{2}$, respectively. However, the offshore Nemo-1X and Sofala- $1 \mathrm{X}$ wells have present-day heat flows of $<40$ and $40 \mathrm{~mW} / \mathrm{m}^{2}$ respectively. Higher present-day heat flows in the onshore wells is consistent with the mechanical laws described above, although the problem appears to be complicated by the absence of the palaeo-sea level curve. For the Jurassic to the present day, the curve should show a maximum during the Late Cretaceous ( $100 \mathrm{Ma}$ ) which then reduced to the present day. Both the Mambone- 1 and Divhine- 1 wells contain some Pleistocene sediments, which could be modelled by incorporating the fall in sea level. The top of the wells occur above sea level at the present day, following deposition of the Pleistocene. This would involve no uplift of either the Mambone- 1 and Divhine- 1 wells during the Pleistocene, and it would therefore not require an increase in heat flow during the Pleistocene to account for emergence of both wells above present day sea-level. The same process regarding fall in sea-level during the Pleistocene also occurred in the Nemo-1X and Sofala-1X wells, although as both wells are currently below sea-level, no emergence above sea-level is required. The decreasing heat flow with time trend for the Nemo-1X and Sofala$1 \mathrm{X}$ wells (although not the actual values used by Mahanjane et al., 2014) would appear to be correct overall. The three major unconformities however, have not been modelled as 
significant uplift events, the higher sea-levels at the times of these erosion events, mean that the wells were more elevated than shown in the Mahanjane et al. (2014) models. Heat flows at the times of these unconformities will therefore have been higher than shown for the Nemo-1X and Sofala-1X wells.

15. The present-day heat flows in the Nemo-1X and Sofala- $1 \mathrm{X}$ wells would be expected to be lower than those at the Mambone- 1 and Divhine- 1 wells, but not by as much as shown in the Mahanjane et al. (2014) study. This is because such a difference in heat flow suggests that the subsidence at the Nemo- $1 \mathrm{X}$ and Sofala-1X well locations was significantly greater than that at the Mambone-1 and Divhine-1 wells, assuming similar depositional environments and water depths for all four locations. But apart from the Nemo-1X well which has the base Upper Jurassic at a depth $>5 \mathrm{~km}$, the other three wells currently have the base Upper Jurassic at depths between 3 and $4 \mathrm{~km}$.

16. In order to derive complex thermal history that can be used to predict petroleum generation, it is best to use of two independent parameters, based on independent methods. Thus, using kinetic models for two maturity parameters, e.g. Vr and biomarkers, to derive the thermal history is not satisfactory, since the use of kinetic theory for deriving the unknown thermal history parameter means that they are not truly independent of each other. This lack of independence means that any problem present in the thermal history derived using one of the T-t based kinetics, such as the absence of increased heat flows during basin inversion, is unlikely to be identified in the other T-t model. As already discussed, a T-P-t based kinetic model would require higher temperatures to produce the same transformation ratio as in a T-t kinetic model. A better approach would be to use one or more T-P-t kinetic models combined with a tectonic-mechanics-thermodynamics model that includes the increased heat flow at the time of extension. The methods used to derive the thermal histories would then be independent of each other, their only link being the subsidence and tectonic histories, and the present day well temperatures.

\section{CONCLUSIONS}

The paper by Mahanjane et al. (2014) represents a typical approach to petroleum systems modelling and petroleum exploration. However, for the reasons set out briefly above, that approach is flawed. Any predictions derived from such models, e.g., the timing and volumes of petroleum generation, are incorrect. An argument often used in favour of 
such models is that they are only models, that have many uncertainties, such as the amount of erosion at unconformities, and the TOC content and kerogen types in the source rock(s) prior to the onset of petroleum generation. The models attempt to present a systematic evaluation of the amounts, timing and phase of the petroleums generated. A counter-argument is that if the methodology incorrectly implements some basic laws of mechanics and thermodynamics, then regardless of the quality of the geological or geochemical models, the model results will be incorrect. These points are made not to criticise the concept of petroleum system modelling, but to outline some problems that have not previously been recognised, and to describe some areas requiring further research.

\section{ACKNOWLEDGEMENTS}

The author would like to thank Drs Ken Peters and Henrik Petersen for their detailed and constructive reviews of this paper which improved the manuscript in terms of scientific content and clarity. The author would also like to thank Dr Clement Uguna and Prof. Colin Snape of the Faculty of Engineering, Nottingham University, UK and my youngest son $\mathrm{Mr}$ Neal Carr, School of Mathematics, Statistics and Actuarial Science, University of Kent, UK for their many useful and varied discussions regarding physical chemistry, mechanics and thermodynamics. The help of the editor with the layout is appreciated.

\section{REFERENCES}

ANITA, D.J. 1986. Kinetic modelling of vitrinite reflectance. Geology, 14, 606-608.

CARR, A.D. 1999. A vitrinite reflectance kinetic model incorporating overpressure retardation. Marine \& Petrol. Geol., 16 353-377.

BURNHAM, A. K., BRAUN, R.L., HGREGG, H.R. and SAMOUN, A.M. 1987. Comparison of methods for measuring kerogen pyrolysis rates and fitting kinetic parameters: Energy and Fuels, 1, 452-458.

CARR, A. D. 2000. Suppression and retardation of vitrinite reflectance: Part 1. Formation and significance for petroleum generation. Journ. Petrol. Geol., 23, 313- 343.

CARR, A.D. and PETERSEN, H.I. 2004. Modelling of the petroleum generation history and volumetric considerations of the coal-sourced Lulita Field, Danish North Sea. Petroleum Geoscience, 10, 107-119. 
CARR, A.D., SNAPE, C.E., MEREDITH, W., UGUNA, C., SCOTCHMAN, I.C. and DAVIS, R.C. 2009. The effect of water pressure on petroleum generation reactions: some inferences from laboratory experiments. Petroleum Geoscience, 15, 17-26.

HARRIS, N.B. and PETERS, K.E. 2012. Analyzing the Thermal History of Sedimentary Basins: Methods and Case Studies. SEPM Special Publication \#103.

JARVIE, D. M. 1991. Factors affecting Rock-Eval derived kinetic parameters: Chemical Geology, v. 93, p. 79-99,

KNAUSS, K.G., COPENHAVER, S.A., BRAUN, R.L., BURNHAM, A.K., 1997. Hydrous pyrolysis of New Albany and Phosphoria Shales: production kinetics of carboxylic acids and light petroleums and interactions between the inorganic and organic chemical systems. Organic Geochemistry, 27, 477-496.

LARTER, S. 1988. Some pragmatic perspectives in source rock geochemistry. Marine and Petrol. Geol., 5, 194-204.

MAHANJANE, E.S., FRANKE, D., LUTZ, R., WINSEMANN, J., EHRHARDT, A., BERGLAR, K., and REICHERT, C. 2014. Maturity and Petroleum Systems Modelling in the Offshore Zambezi Delta Depression and Angoche Basin, Northern Mozambique. Journ. Petrol. Geol., 37, 329-348.

McKENZIE, D. 1978. Some remarks on the development of sedimentary basins. Earth and Planetary Science Letters 40 25-32.

MICHELS, R., LANDAIS, P., PHILP, R.P., TORKELSON, B.E., 1994. Effects of pressure on organic matter maturation during confined pyrolysis of Woodford kerogen. Energy and Fuels, 8, 741-754.

MIDDLETON, M.F. 1982. Tectonic history from vitrinite reflectance. Geophysical Journal of the Royal Astronomical Society 68, 121-132.

MONTHIOUX, M., LANDAIS, P., DURAND, B., 1986. Comparison between extracts from natural and artificial maturation series of Mahakam Delta coals. Organic Geochemistry, 10, 299-311.

RITTER, U. 1984. The influence of time and temperature on vitrinite reflectance. Organic Geochemistry, 5, 362-379.

SNOWDON, L.R. 1979. Errors in Extrapolation of Experimental Kinetic Parameters to Organic Geochemical Systems. AAPG Bulletin, 63, 11128-1134.

STAINFORTH, J.G. 2009. Practical kinetic modeling of petroleum generation and expulsion. Marine \& Petrol. Geol., 26, 552-572. 
SWEENEY, J.J. and BURNHAM, A.K., 1990. Evaluation of a simple model of vitrinite reflectance based on chemical kinetics: AAPG Bulletin, 74, 1559-1570.

TAO, W., ZOU, Y-R., CARR, A., LIU, J. and PENG, P’a. 2010. Study of the influence of pressure on enhanced gaseous petroleum yield under high pressure-high temperature coal pyrolysis. Fuel, 89, 3590-3597.

UGUNA, C. N., CARR, A. D., SNAPE, C. E., MEREDITH, W. and CASTRO-DÍAZ, M. 2012. A laboratory pyrolysis study to investigate the effect of water pressure on petroleum generation and maturation of coals in geological basins. Organic Geochemistry, 52, 103-113.

UGUNA, C.N., CARR, A.D., SNAPE, C.E. and MEREDITH, W. 2015. High pressure water pyrolysis of coal to evaluate the role of pressure on petroleum generation and source rock maturation at high maturities under geological conditions. Organic Geochemistry, 78, 44-51

WAPLES, D. W. 1998. Basin modelling: how well have we done? In: Basin Modelling: Practice and Progress. Duppenbecker, S. J. and Iliffe, J. E. (Eds) Geological Society, London, Special Publications, 141, 1-14.

WAPLES, D.W., KAMATA, H. and SUIZU, M. 1992. The art of maturity modeling. Part 1. Finding a satisfactory geological model. AAPG Bulletin, 76, 31-46.

WELTE, D.H., HORSFIELD, B. and BAKER, D.R. 1997. (eds). Petroleum and basin evolution: Insights from petroleum geochemistry, geology and basin modelling. Springer

WOOD, D.A., 1988. Relationships between thermal maturity indices calculated using Arrhenius equation and Loptain method: Implications for petroleum exploration. AAPG Bulletin, 72, 115-134.

ZOU, Y-R. and PENG, P. 2001. Overpressure retardation of organic-matter maturation: a kinetic model and its application. Marine and Petrol. Geol., 18 707-713.

Figures

1. Schematic diagram showing the relationship between changes in burial depth and Top Basement heat flow as controlled by mechanical work for a) subsidence, and b) inversion. Arrows indicate increasing burial depth and heat flow.

2. a) Methane and (b) total gas yields for two Chinese coals pyrolysed at $380{ }^{\circ} \mathrm{C}$ for 24 h, and at pressures between 50 and $250 \mathrm{MPa}$ (after Tao et al., 2010). 
3. a) Oil and gas yields (mg/g) obtained from a perhydrous Svalbard coal (original S2 = $273 \mathrm{mg} / \mathrm{g} ; \mathrm{HI}=347 \mathrm{mg} / \mathrm{g}$; $\operatorname{Tmax}=440{ }^{\circ} \mathrm{C} ; \mathrm{VR}=0.68 \% \mathrm{Ro}$ ) pyrolysed at $380{ }^{\circ} \mathrm{C}$ under pressures between 230 and 900 bar (after Uguna et al., 2015), and b) vitrinite reflectance results obtained from the Svalbard coal pyrolysed at 350, 380 and $420{ }^{\circ} \mathrm{C}$ and at pressures between 175 and 900 bar (after Uguna et al., 2015). 
Fig. 1

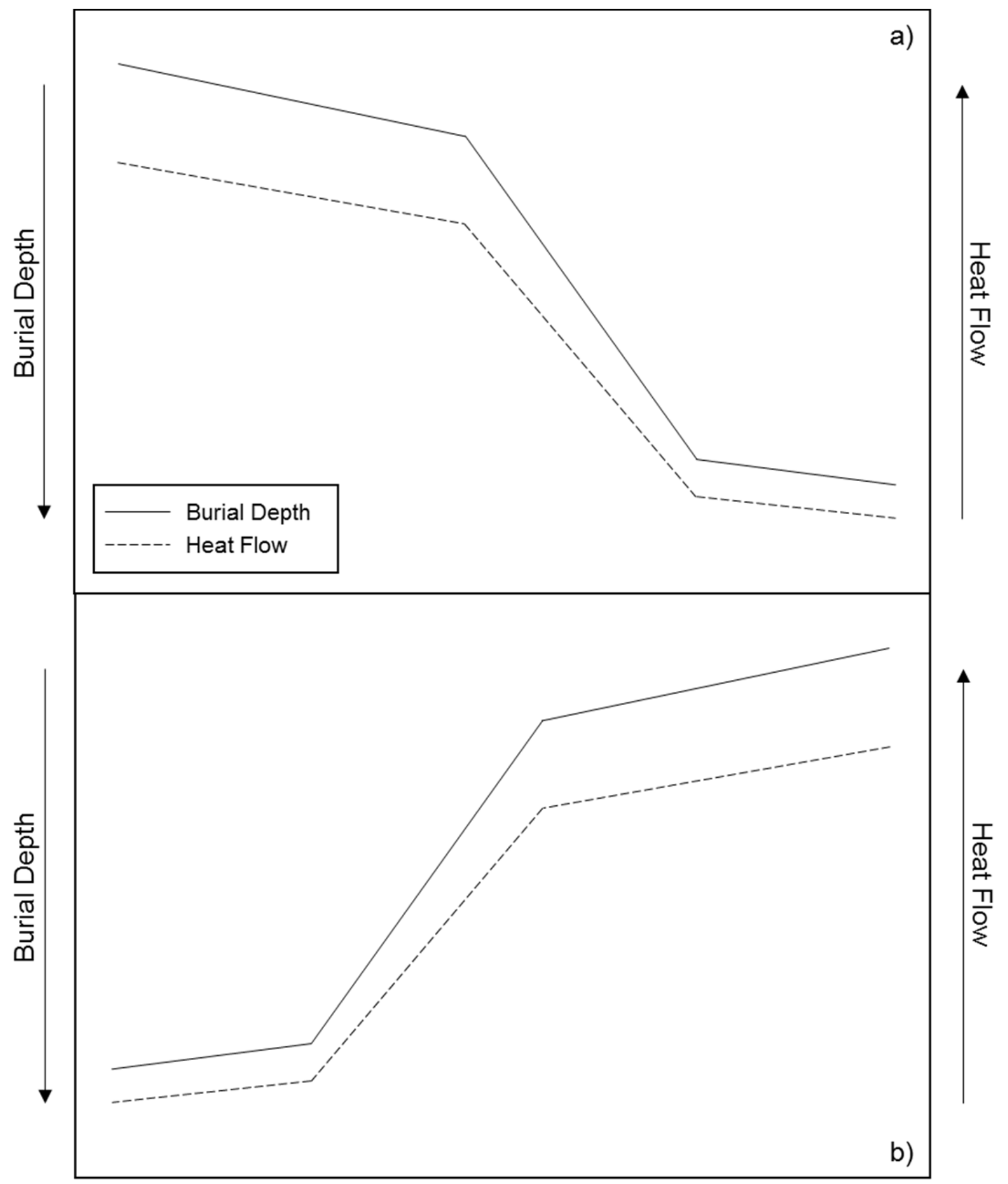


Fig. 2
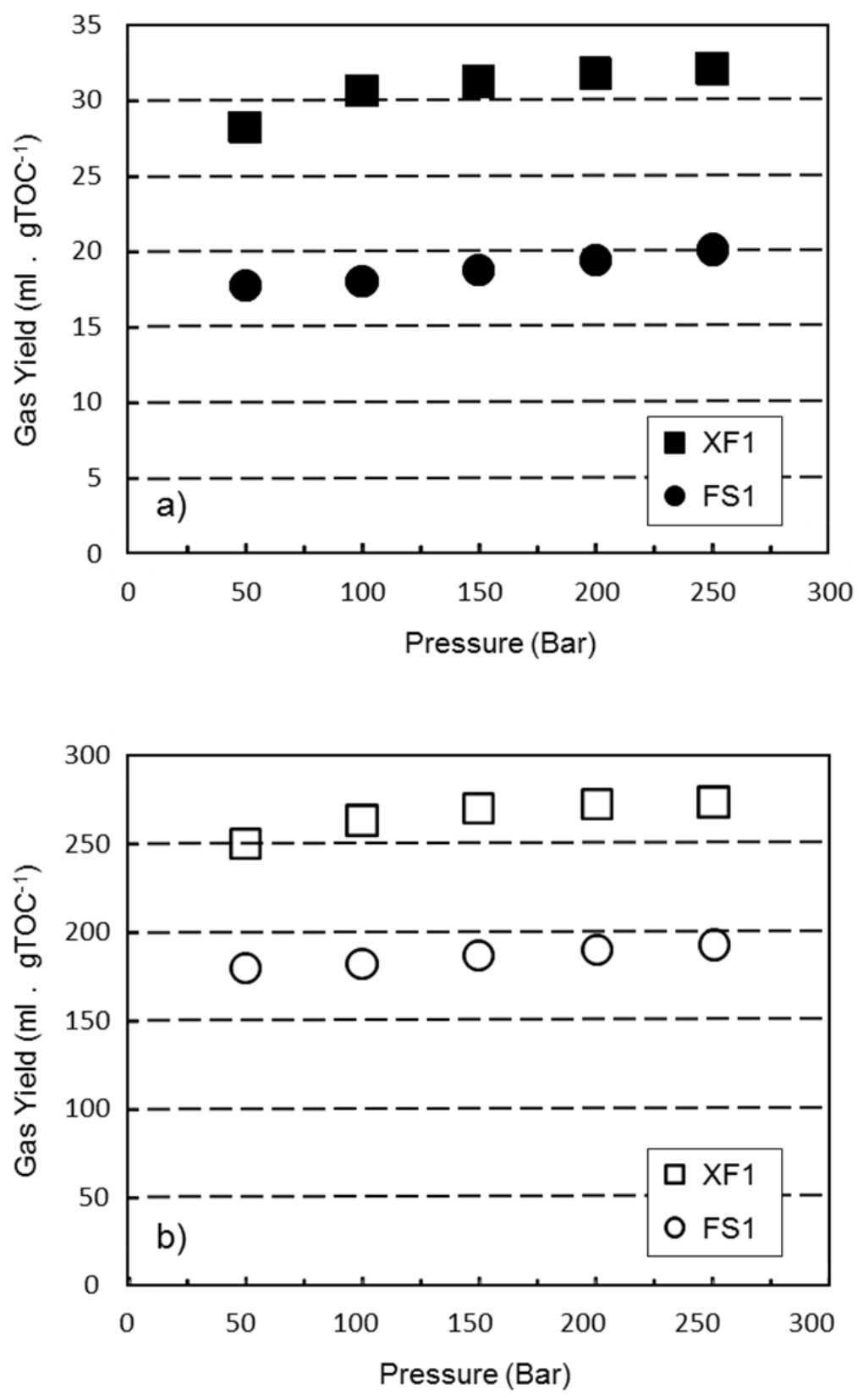
Fig. 2
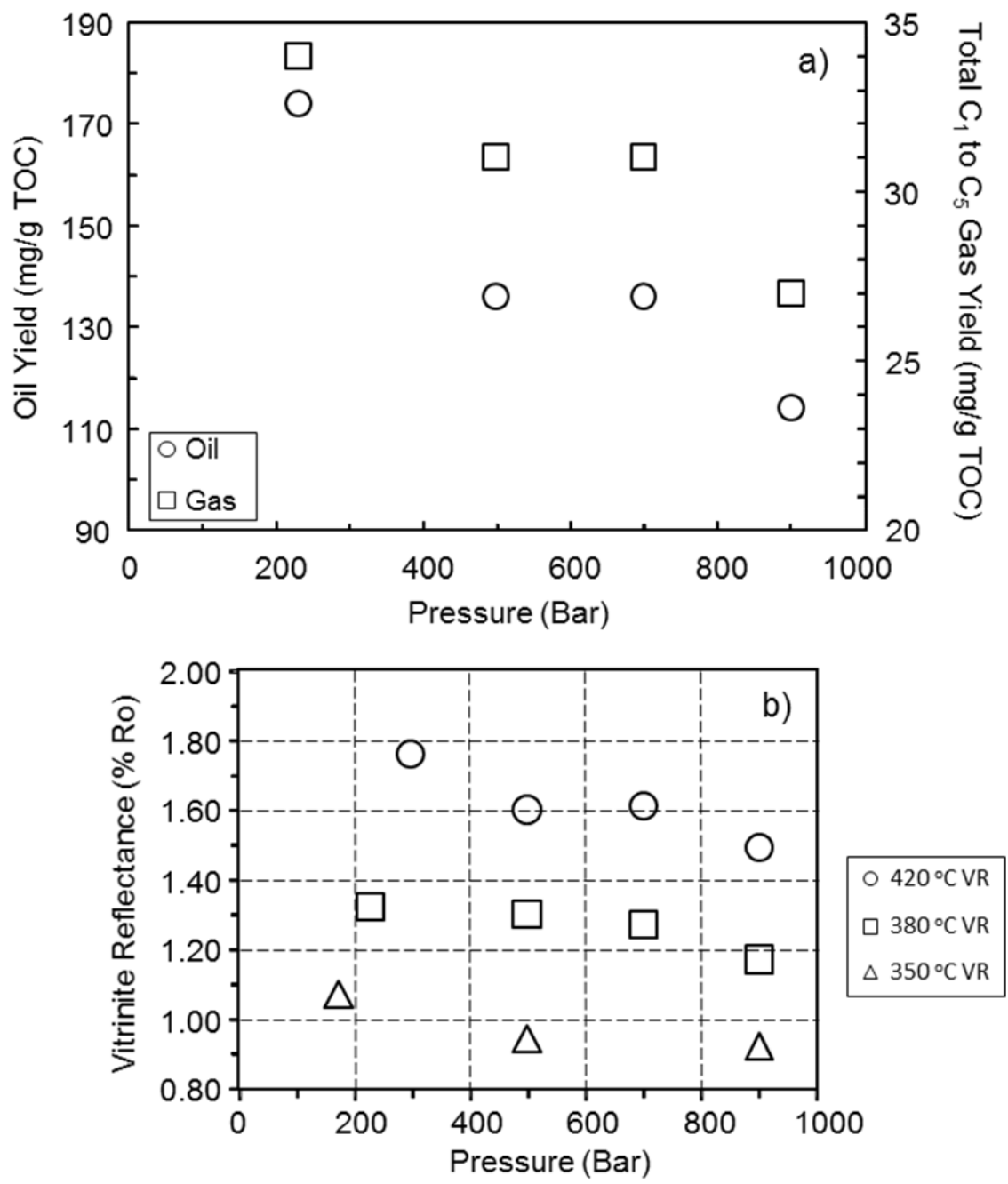